\title{
Perceptions and Experiences of Mobile-Assisted Language Learning for IELTS Preparation: A Case Study of Indonesian Learners
}

\author{
Soulaya Lestary
}

\begin{abstract}
This qualitative case study investigated Indonesian English as Foreign Language (EFL) learners' perceptions and experiences of IELTS m-learning preparation. It aimed to explore the learners' perceived advantages and challenges of IELTS m-learning, self-directed m-learning strategies, and the extent to which m-learning supports their IELTS preparation. Data collected through interviews were analyzed following the Framework for the Rational Analysis of Mobile Education (FRAME). The findings revealed that there are some correlations between the advantages and the challenges of IELTS mobile learning adoption. This study also found that the learners' learning strategies for IELTS preparation were mostly related to motivation in which it drove them to expand some efforts towards their IELTS practices. IELTS mobile learning was also found to have supported their learning experience to a great extent.
\end{abstract}

Index Terms-The FRAME model, IELTS, MALL, self-regulated learning.

\section{INTRODUCTION}

In the 21st century, the dominance of English has reached almost all sectors of our life including science, technology, computers, business, and education [1], [2] This makes English becomes lifelong learning as it can be done in various conditions and situations to match one's needs [2]. On the other side, the advancement of technology development paves the way for a more attractive, effective, and feasible form of learning [3], [4]. Particularly, English learning through mobile computing devices have not only enabled ubiquitous and effective learning, but it has also made studying English more personalized and fun [5].

While mobile-assisted language learning (MALL) benefits formal education, mobile learning (m-learning) also potentially encompasses the learning process outside classrooms as it can be done anywhere and anytime [6]. This sparks new challenges as language learning in school is based on a set of the curriculum with the guidance of a teacher, whereas, English mobile learning requires self-exploration and self-assessment [2], [7], [8]. Therefore, investigating the later learner's experience is essential.

A. Indonesian Context

As being proficient in English becomes a global need [9],

Manuscript received September 26, 2019; revised November 23, 2019. This work was supported in part by SEC Alumni Grants Group and the LPDP (Indonesia Endowment Fund for Education).

Soulaya Lestary is with the University of Bristol, UK (e-mail: soulayalestary@gmail.com).
British Council reported in 2013 that English proficiency gets a high demand of up to $40 \%$ in Indonesia [10]. Studies in 2017 by Tracer Study Universitas Indonesia (TSUI) and AFS Global Research Study [11] have indicated that Indonesians youths, in particular, are motivated to be fluent in English for jobs and studying abroad purposes. This is because business sectors globally and universities in English-speaking countries commonly require TOEFL (Test of English as Foreign Language) or IELTS (International English Language Testing System) score to prove their English ability; moreover, MALL has been proven to support their English learning [3], [12]. However, most of them only focused on the impact of mobile phone use on general English language learning. They lack focus on the use of mobile learning in the English proficiency tests [13], particularly learning IELTS in informal settings. Thus, this research focuses on the use of mobile devices in IELTS preparation within the context of Indonesian learners, and it will explore their perspectives and experiences, their learning strategies, and the extent to which mobile learning impacts their IELTS preparation test.

\section{LITERATURE REVIEW}

\section{A. Understanding Mobile Learning}

The term mobile learning, or m-learning, is simply understood as a process of learning through mobile phones [14]. According to Guild (2009), m-learning is defined as:

"An activity that allows individuals to be more productive when consuming, interacting, or creating information, mediated through a compact digital portable device that the individual carries on a regular basis and has reliable connectivity and fits in a pocket or purse”. [15, p.3]

However, the mentioned literature defined m-learning with relatively less attention to the process and aspects that intertwined during the learning process. Koole [16] emphasizes a more detailed scope of mobile learning which involves three main aspects; device, learners, and social. Mobile learning is "a process resulting from the convergence of mobile technologies, human learning capacities, and social interaction"'[16, p.25] Koole's m-learning definition will be used for this research as it covers the three main aspects that correlate with language learning.

\section{B. Mobile Learning in EFL Education}

As mobile computing devices, for example, smartphones and tablet computers, have grown popular among societies, it has affected the way the communities learn and acquire a 
second language [2]. Consequently, there has been a growth in the area of mobile-assisted language learning (MALL) in which language learners and enthusiasts use mobile technology to study languages [17], [18]. Particularly, it has become prominent for English as Foreign Language (EFL) learners [5], [8]. Chen and Kessler [5] highlight that EFL learners use a mobile phone to study English in informal settings because it increases their motivation, satisfaction and fosters ubiquitous learning and effectiveness. MALL's adoption ranges "from language drill and practice to authentic communication" such as listening to audio and watching videos to learning grammar, vocabulary and reading $[8$, p.301].

Likewise, researches on mobile learning and English has involved an English proficiency test [19]-[21]. The literature points out that the most prominent tests are the International English Language Testing System (IELTS) and the Test of English as Foreign Language (TOEFL) and the study were mostly explored within institutional settings instead of informal settings. There was no clear explanation of how they may be carried out beyond classrooms, specifically in learning IELTS through handled devices.

\section{Mobile Learning as Self-regulated Learning}

M-learning for language learners is mostly considered as self-regulated learning [8], [18], because it requires autonomous learning, sharing, knowledge construction, and thus language learners should be independent throughout the process [22]. The learners' abilities to appropriately decide on what, when, where, and how to learn is similarly important with their self-motivation "to behaviorally and cognitively engage in learning whenever/wherever they themselves realize it is needed" in order to have an effective mobile learning experience [23, p.367]. Besides that, the learner's motivation is usually driven by their perceived usefulness and personal innovativeness of the mobile computing devices. [24].

\section{The FRAME Model}

FRAME (The Framework of Rational Analysis of Mobile Education or the FRAME-model) by Koole [16] offers an inclusive model which analyses the relations among three aspects; the mobile technologies used (device), individual learning capacities (learner), and the social aspects during the learning process (social). The FRAME model is represented by a Venn diagram (Fig. 1) that shows the interaction among a mobile device (D), a learner (L), and social aspects (S) [16].

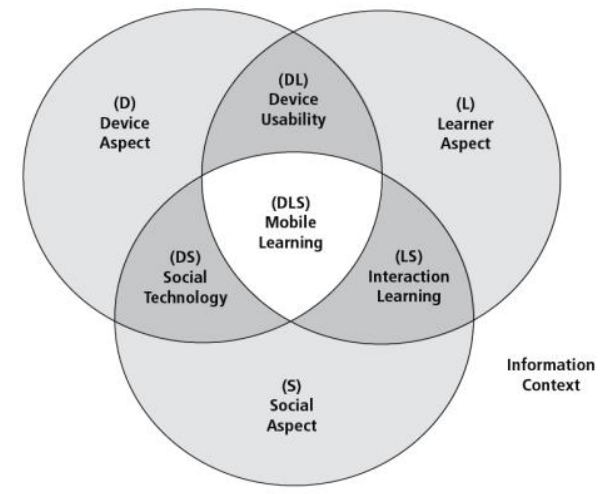

Fig. 1. The FRAME model.
There are 26 key components addressed in this model, and they are categorized in each of the aspects which overlaps one another during the interaction:

- Device aspect:

Physical characteristics, input capabilities, output capabilities, file storage and retrieval (e.g. device's capacity to store files and support external disk), processor speed (e.g. device's ability to react to human's input), and error rates (e.g. malfunction caused by hardware or software flaws)

- Learner aspect:

Prior knowledge, memory (e.g. using of contextual cues to memorize), context and transfer (e.g. using information aids to memorize, understand and transfer of concepts to varied contexts), discovery learning (e.g. the ability to filter, choose, and recognize relevant information to solve novel problems), and emotions and motivations (e.g. learner's feelings towards a task and their motivation to accomplish it).

- Social aspect:

Conversation and cooperation (e.g. social constraint and following the 4 communication maxims - quantity, quality, relation, and manner), and social interaction (e.g. using signs and symbols to cooperatively communicate).

- Device usability:

Portability, information availability (e.g. information can be accessed across time and space), psychological comfort (e.g. mobile app design is comprehensive and easy to use for learning), and satisfaction (e.g. device's physical appearance and functionality).

- Social technology:

Device networking (e.g. Wi-Fi and cellular connectivity), system connectivity (e.g. access of internet and document transfer protocols), and collaboration tools (e.g. tools which allow users to co-author documents).

- Interaction learning:

Interaction (e.g. learner-learner, learner-instructor, learner-content), situated cognition (e.g. learning tasks are situated within authentic contexts), and learning communities (e.g. communities of practice).

- Mobile learning process:

Mediation (e.g. the change of interaction between learners and information), information access and selection (e.g. recognizing information which is suitable and accurate), and knowledge navigation (e.g. selecting, manipulating, and applying information based on the learner's need and context).

\section{METHOD}

This research aims to explore Indonesian EFL learner's perceptions and experiences of mobile learning practices in IELTS preparation and investigate the extent of mobile devices use in learning IELTS. The following research questions were used to further investigate this topic:

1). What are the learners' perceptions of mobile learning's advantages and challenges in their IELTS preparation?

2). What are the possible independent learning strategies of the learner's IELTS m-learning?

3). To what extent m-learning adoption supports Indonesian EFL learners' IELTS preparation? 
Although similar studies around the world have researched the relation of mobile-assisted language learning to the influence of second language acquisition [6], [18], there are still limited research on this area in relation to EFL learners and IELTS preparation, particularly within Indonesian context. Therefore, these research questions aim to fill the gap in research.

To answer the research questions, this study used an interpretivist approach to focus on how the participants interpret, understand, and experience the social world [25], in this case, mobile learning in IELTS preparation test. A qualitative method was needed to explore in-depth interpretation and perspectives which include feelings, opinions, and beliefs [26], and thus it is very subjective [27]. A case study was then used as it was suitable to find out about a certain type of person, people, or social context, so the researcher was able "to effectively understand how it operates or functions.” [27, p.225].

\section{PARTICIPANTS}

The participants were selected with a purpose (or purposive sampling) and do not represent general and massive populations [26]. Accordingly, the participants of this research were Indonesian students at the University of Bristol who received a scholarship from the Indonesian Government. They had to have taken the IELTS test and used mobile devices during their IELTS preparation. I also used special expertise in selecting the participants [27] because I was also part of the scholarship awardees and aware of the scholarship process which included mastering IELTS at a certain band score (minimum 6.5). In other words, the potential participants had already acquired a good IELTS score. A total of ten participants who mostly used a smartphone and laptop for their IELTS preparation were interviewed and Table I describes the participants in brief.

TABLE I: RESEARCH PARTICIPANTS' DESCRIPTION IN BRIEF

\begin{tabular}{|c|c|c|c|c|}
\hline Name & Age & $\begin{array}{l}\text { IELTS } \\
\text { score }\end{array}$ & Backgrounds & $\begin{array}{l}\text { Learning } \\
\text { Location }\end{array}$ \\
\hline Kim & 26 & 7.5 & $\begin{array}{l}\text { English Literature Graduate } \\
\text { and Private English Tutor }\end{array}$ & Semarang \\
\hline Gege & 31 & 7 & $\begin{array}{l}\text { Accounting Graduate and } \\
\text { Civil Servant }\end{array}$ & Jakarta \\
\hline Donrio & 37 & 7.5 & $\begin{array}{l}\text { English Literature Graduate } \\
\text { and Private English Tutor }\end{array}$ & Bali \\
\hline Mawar & 25 & 7 & Social Work Graduate & Bandung \\
\hline Lina & 32 & 7.5 & $\begin{array}{l}\text { English Education Graduate } \\
\text { and English Teacher }\end{array}$ & Jakarta \\
\hline Bella & 35 & 7.5 & $\begin{array}{l}\text { Accounting Graduate and } \\
\text { Civil Servant }\end{array}$ & Jakarta \\
\hline Cici & 24 & 6.5 & $\begin{array}{l}\text { English Education Graduate } \\
\text { and English Teacher }\end{array}$ & Jambi \\
\hline Ana & 28 & 7.5 & $\begin{array}{l}\text { Engineering Graduate and } \\
\text { Lecturer }\end{array}$ & Bandung \\
\hline Indah & 27 & 7.5 & $\begin{array}{l}\text { English Literature Graduate } \\
\text { and Private English Tutor }\end{array}$ & Amsterdam \\
\hline James & 26 & 7 & $\begin{array}{l}\text { International Relation } \\
\text { Graduate }\end{array}$ & Yogyakarta \\
\hline
\end{tabular}

The table shows the participant's brief descriptions which include age, their IELTS score, educational and work backgrounds, and learning location. As previously explained, these indicate that the participants are very specific and subjective according to their personal experience.

\section{Data Collection Methods and Procedure}

Data collection in this research was carried out through a semi-structured interview, which took approximately 50-60 minutes and conducted in English. This helped me to have some guidelines in conducting the interview, and at the same time, it still gave me the flexibility during the interview to ask and explore the questions whenever appropriate in an unbiased manner [28]. It encouraged the interviewee to be an "informant" instead of a respondent who would not only offer valuable information regarding the issue but also "corroboratory" evidence and "initiate the access to such sources [27, p.90].

Furthermore, the interview sessions were conducted face-to-face since most of the participants were the University of Bristol's postgraduate students. I also made sure that the place and condition of the interview were quiet, comfortable, and had a stable internet connection for the online interview. This helped me concentrate during the interview and it resulted in a very clear audio recording [29]. Also, it kept the length of conversation not too short, but according to what had been planned [27].

\section{DATA ANALYSiS FrameWORK}

Qualitative thematic analysis was used to analyze the data gathered from the semi-structured interviews. This allowed me to investigate the data at different levels in order to craft a refined synthesis and interpretation of the data collected, and thus provide detail and rich evidence [30]. Most of the qualitative thematic analysis process was conducted using a computing software - NVivo11 to code the data into theme or nodes and sub-nodes. Such software supports "conceptualization of data by the analyst" and enables "extended hyperlinking facilities which allow the analyst to create links between different aspects of the data set." [29, p. 207]. Also, the process of the thematic analysis was done based on Matthews and Ross' [25] guidelines which involved organizing the data, identifying initial key themes, explore the data to find meanings, looking for relationships among the chunk of data, and explain the similarities, differences, and the distinguished relationships.

The collected data were explored to find meanings via NVivo11 which were followed by looking for relationships among the data sets. During this process, data reading was done through interpretative and reflexive ways as suggested by [25] so that the data, the FRAME model, and the research questions can be connected. Nonetheless, as thematic analysis is flexible, the use of inductive approach along the process was also possible whenever new key themes emerged as this would help this study in producing rich descriptive data [29]. Therefore, both deductive and inductive approach was carried out to produce detail and rich data. In the first phase of the analysis, there were 4 main themes and 17 sub-themes. The initial main themes were Challenges of Mobile Learning, Advantages of Mobile Learning, Learning 
Strategies, and the Extent of M-learning Impact. However, along the analysis process, the participant's concern on getting direct feedback was predominantly mentioned and aroused by the participants, so 2 emerging sub-themes into Learning Feedback as an additional inductive main theme were codded. Next, several nodes that were less relevant and overlapping with each other were omitted. Then this study began focusing on finding references from the transcript that back up the final five key themes as seen in Fig. 2.

Nodes
Name Files
The extent of M-Learning Impact

Fig. 2. Final key themes.

Lastly, the findings were described and discussed following the FRAME model and related literature. In order to support the arguments, I included verbatim quotations from the participant [26].

\section{RESULTS AND DISCUSSIONS}

This study employed the FRAME model and related literature to analyze the Indonesian EFL learner's perceptions and practices of learning IELTS with the support of mobile devices.

\section{A. RQ1: Advantages and Challenges of m-Learning}

\section{1) EFL learner's perceptions of m-learning advantages}

The EFL learners' views of the advantages of mobile learning adoption in practicing IELTS correlates with the device aspect and device usability from Koole's FRAME model (see section II.D). Some of the most cited benefits of the device aspect are its physical characteristics (e.g. compact and small) and input-output capabilities (e.g. storing and retrieving files) which allowed the learners to study while moving around. They reported that several tools and apps in their smartphone, for examples, YouTube, Spotify ${ }^{1}$, Podcast ${ }^{2}$, and Web Browser enable them to practice their listening and reading skills more conveniently across time and spaces, for examples, while waiting for the doctor, commuting by train or bus, and riding on a motorbike. This connects with Loewen et al.'s findings [18] who supported that the use of mobile phones had greatly advantaged their research participants to learn foreign languages in flexible ways anytime and anywhere.

Moreover, the participants emphasized that mobile devices' physical characteristics and input-output capacities allowed them to learn in flexible ways. The words "anytime and anywhere" were mostly mentioned by all participants when asked about their reasons for IELTS mobile learning preference. This corresponds to the FRAME model which

\footnotetext{
${ }^{1}$ Spotify is a digital platform that provides access to millions of songs and other content from artists in all countries via music, podcast, and video streaming.

${ }^{2}$ A podcast is a set of series of digital audio or video files which can be listened or upload by listeners or content creators.
}

pointed out the concepts of mobile usability - such as portability which leads to easy access to information anytime and anywhere. An implication of this is the possibility that the learners are able to accomplish a task quickly and memorize the knowledge related to IELTS practices as they can access and recall concepts more easily [16].

The anytime and anywhere access reminds of what Erstad [31, p.26] call the "learning lives" of young people who "move between different contexts of learning, both offline and online, in a constant flow of activities." Erstad also mentioned that youth spend most of their time in media use, and thus it matches the participants of this research who were all young people (see section IV). One learner, Kim, emphasized that "if writing Instagram caption in English also count as a part of learning [IELTS writing], then I would say yes...I write captions, tweets everything in English." These finding may help us to understand that mobile learning is part of their life, and therefore contributes to their view of the advantages of mobile learning use in IELTS preparation.

Meanwhile, the findings showed that some of the learners learned IELTS without any help from other learners or a tutor. This contradicts with that of Koole's FRAME model which emphasized social interaction as the main aspect of successful mobile learning. The learner's views on self-study experience in IELTS mobile learning is more relevant to Byrne and Diem's empirical research [7]. Their researcher, in contrast to the FRAME model, significantly showed that mobile learners are more interested in self-learning. This finding has important implications for taking into account the participants' different demographics (see table 1. in section IV). It can, therefore, be assumed that their perceptions of mobile learning's benefits are highly dependent on their educational and professional backgrounds, culture [32], and locations at the time of learning.

2) The EFL learner's perception about mobile learning challenges

Despite the learners' good IELTS score, they view self-directed learning and device-related disturbances as the main challenges during their IELTS preparation. As mobile learning is regarded as self-learning by most participants in which it is similar to the study conducted by [23], some of them gained feedback only by comparing and contrasting the abundant learning materials available online. Six out of ten participants had no tutor to rely on, and thus self-assed themselves. Lina who had only two weeks to learn IELTS before the actual test stressed that it was difficult for her to receive "live" feedback from "live" person. The difficulties in getting real-time feedback to validate their understanding throughout the learning process via mobile phones may not be suitable for skills that require in-depth learning tasks such as fluency in speaking and writing because it takes a long time to process [33]. Thus, the fact that some participants only had short amount of time to study the four IELTS skills - listening, reading, speaking, and writing, but still managed to get good score indicates that the successes of mobile learning also depends on the prior knowledge of the "learner aspect" from the FRAME model (see section II.D). it is worth to note that some participants graduated from English departments and were English teachers (see table 1 in section 
IV) who have years of experiences studying, teaching, and practicing English. Their knowledge navigation, therefore, with the use of previous knowledge in discovering, exploring, selecting, filtering information to find relevancy and accuracy of the knowledge required contributes to the successful use of mobile learning [16]

In addition, distractions coming from digital applications' notifications are also the challenges mostly mentioned by the participants. They highlighted that social media applications such as WhatsApp, Instagram, and Twitters usually disturb their learning process. This associates with the learning lives of digital youth who mostly spend time on media as also discussed previously in section VII.A. However, three highly motivated learners did not seem to agree with the social media distractions when asked about mobile learning challenges. Instead, they focused on how small screen size and on-screen keyboard made learning certain IELTS skills difficult, particularly in practicing IELTS writing simulation test in which the real IELTS test requires handwriting as mentioned by one participant. Meanwhile, Indah expressed that practicing writing through mobile Microsoft word was not convenient, so she switched from smartphone to laptop to practice her IELTS writing on a bigger screen. On a similar note, another learner stated that she could stay focus by installing an app-blocking application to prevent her from opening other applications on her smartphone other than IELTS learning related. Thus, these relates to the idea that self-motivation plays an important factor to make mobile learning effective [23] since the learners take full control of their learning progress

\section{B. RQ 2: Self-directed Mobile Learning Strategies for IELTS Preparation}

\section{1) Learning strategies concerning motivation}

The learners interviewed identified several self-learning strategies to using mobile devices in preparing themselves for the IELTS test, and the strategies to keep motivated were reported to be the most important. One learner asserted that: "Without a goal, I will stay in my bedroom and do nothing" (Lina). A strong relationship between motivation and sustainable use of mobile learning has been reported to play a significant role [34]. This study raised concern on students' voluntary participation in mobile learning which greatly depends on intrinsic motivation. Similar to that reviewed in [35], the learning strategies reported by the EFL participants were classified into: 1) goal-directed activity and 2) effortful behaviours, and the detail findings will be described and discussed.

When asked about motivation, the participants were unanimous in the view that their purpose of studying IELTS was highly correlated to their goal of studying aboard and achieving scholarship. As one interviewee said: "I wanted to apply for the scholarship, and they have like the standard IELTS score that I needed to get ... because of that I needed to use mobile phones every day" (Indah). This is also related to the Learner Aspect of the FRAME model in which a learner's willingness is affected by his/her desire to accomplish a task [16]. All of the participants believed that they had a precise goal which was pursuing postgraduate study in the UK with the help of the Indonesian government fully-funded scholarship, and thus mobile technological devices were suggested to be a helpful learning tool in reaching their target score for IELTS. It can, therefore, be assumed that the learner's learning strategy was highly driven by their motivation by having set a specific goal in which influenced their foreign language achievement, particularly their IELTS score.

Eventually, the participants emphasized some efforts done as their learning strategies to support their IELTS learning via mobile phones. It was suggested that the IELTS test should be paid weeks or months in advance to know the actual IELTS test date arranged for them. Meanwhile, some learners felt that they had to set a timeline and daily learning goals to boost their motivation during their IELTS preparation. Interestingly, one learner stated that certain mobile educational applications - such as British Council App, supported the learners to track their daily learning progress and offers "a reward like if we could achieve some goals from that games" (Mawar). This finding is consistent with that of [18] who mentioned the positive aspect of gamification in Duolingo, a foreign language learning application. However, a note of caution is due here since paying the test in advance and planning their IELTS practice timetable and progress can, therefore, be assumed as intrinsic motivation. Two participants expressed that they needed encouragements from their parents and friends to keep motivated during their IELTS preparation. One of them mentioned that her friends encouraged her through WhatsApp to monitor and check on her learning progress because she believed when learning IELTS through mobile phones, there was the absence of teacher who would guide and motivate her. Therefore, such extrinsic motivation is also likely to influence the learners' learning strategies.

\section{2) Learning strategies related to self-directed learning}

All participants agreed that mobile learning is a form of self-learning which is also reported by the previous studies (see section II.C). They described that mobile phones are just tools to support their study, "like a medium that can facilitate [the learners] in accessing the materials, not really like a tutor" (Donrio). However, from the data, it can be seen that the strategies related to the use of mobile phones in learning IELTS are limited to using mobile digital applications for practicing listening and reading skills.

Majority of participants believed that mobile phones were helpful in their IELTS listening and reading practices. They stated that there are different strategies to that. Predominantly, for IELTS listening preparation, they pointed out that they listened to audio/video related applications on their mobile phone including YouTube, and "podcasts on Spotify because they have a wide range of topics and themes" (Kim) ranging from formal-informal genres to comedy. Other learners added that on his smartphone, he "downloaded [samples of IELTS listening test] ... and when [he is] going to bed ... then [he] listened just to make [his] ears familiar with this English speaking audio" (Donrio), and "listen to many English songs to help [him] also in recognizing some words or learning the pronunciation" (James). As for IELTS reading test, some learners also mentioned using Google search engine to read online newspapers and find samples of the 
IELTS reading tests and materials related to tips and tricks to pass the test, and then practiced the IELTS simulation test independently by using a timer and referring to the answer keys for the assessment. Nevertheless, considering that some of them had taken the IELTS test before, four of them enrolled in a face-to-face IELTS tutoring program, and half of them are English teachers, it is important to bear in mind that their skills in selecting relevant online resources vary. As one interviewee put it:

"Before I learned [IELTS] independently I took like a private class for IELTS for about 3 months and probably for the use of mobile phone itself I use it sometimes like mostly almost 2 hours a day" (James)

These findings, therefore, corresponds to that of [16] who emphasized on learners' prior knowledge in the success of mobile learning practices in which it may influence their ability to comprehend new concepts.

One unexpected finding was that the learners' strategies to practice IELTS listening and reading test were mostly passive. They described that when using mobile phone for learning, most of them would only watch the videos, listen to audios, play games through certain vocabulary or grammar apps, and read comments made by other learners. This is similarly related to 'learner-content interaction' that of Moore (1989) in [16] in which the learners are believed to demonstrate learning through the negotiation of meaning between the author's (of the learning materials) and their interpretation. Surprisingly, some learners reported that they joined online learning communities, such as FutureLearn and IELTS Learner Community on Facebook, solely to observe and grasp the knowledge from the chats of other members in the community. These results are likely to be related to mobile learning as self-directed learning as mentioned previously.

\section{RQ 3: The Extent to Which m-Learning Supports IELTS Preparation}

Prior studies have noted the significance of mobile device use in language learning (see section II.B). However, it is still not clear to what extent mobile learning may impact IELTS learning for EFL learners. Although the leaners reported that getting direct feedback was difficult in IELTS mobile learning, they expressed that using mobile phones helped them reached their IELTS target score because of the convenience and efficiency that it offers. Thus, the learners believe that, to a large extent, mobile learning supported their mobile learning experience for their IELTS preparation.

The participants, on the whole, demonstrated their contentment in ubiquitous learning through mobiles phones which are considered substantial for providing personalized learning "even in a futsal pitch while waiting for the next game" (Donrio). One learner argued that compared to his first IELTS preparation through in-class tutoring program, his second IELTS preparation which solely depended on the use of mobile phone had helped him a lot in improving his ELTS test score. He believes that mobile learning offers him more casual learning which he did not experience in a face-to-face IELTS preparation program. For example, he emphasized that "learning by mobile phone was easier because [he] could use [his] own pace" (James) without any pressure from tutors or peers. Another important finding, some participants reported that flexible learning allowed them to access IELTS learning materials anytime and anywhere which corresponds to that of [18] regarding information accessibility in mobile-assisted language learning. Nevertheless, opinions differed as to whether or not easy access of information gave positive or negative impacts. Some learners argued that information accessibility may help in getting abundant free IELTS learning sources; in contrary; some of them believe information accessibility at anytime and anywhere might distract them in staying focus when it comes to learning in crowded environments. Nevertheless, for mobile learning to be successful, the participants had some characteristics in common and one of them is the ability to select information based on their situation and needs [16]

Equally important, the learners viewed IELTS mobile learning to have saved their time and money. They reported that they could save time as they could multitask on several agendas while at the same time learn IELTS. One participant stated that IELTS tutoring programs are expensive, so with the use of internet access through mobile phone, she could obtain any IELTS sources from many countries for free.

In like manner, although the learners believe mobile learning supports their IELTS preparation, they found getting direct feedback was difficult during their learning process. For writing and speaking, the learners said that they relied on their prior knowledge and ability to correct themselves by comparing their answers to high IELTS band samples. In this respect, the data indicate that IELTS preparation through mobile learning requires the learners to have good critical thinking skill [36].

\section{CONCLUSION}

Focusing on Indonesian EFL learners use of mobile devices for IELTS preparation, this paper has revealed some correlations between the perceived benefits and challenges. This study has shown that although mobile device aspects (e.g. compact and small) and usability (file storage systems) were reported to have eased IELTS learning anytime and anywhere because it is portable, the small screen size limits the learning of certain IELTS test sections, particularly writing. The most obvious finding to emerge from this study is that using mobile phones to learn IELTS is mostly regarded as self-learning in which the learners had to self-assessed themselves during their IELTS preparation, especially when two participants had not interacted at all with any IELTS learners or teachers. This study adds to the growing body of research that indicates the role of motivation in affecting the Indonesian EFL learners' learning strategies. One of the more significant findings to emerge from this study is that mobile learning adoption has helped IELTS learners to a great extent. Particularly, this study has identified how mobile learning makes IELTS preparation more convenient and efficient. On the other hand, the data analysis has shown that learning IELTS through mobile phone might be difficult in obtaining real-time feedback to guide their understanding and validate their knowledge. In this way, the study has shown that even though IELTS mobile learning had supported the learners to study all the IELTS test sections - 
listening, reading, writing, and speaking, some learners still require further assistance from other IELTS learners or tutors to practice certain skills, such as writing and speaking.

This study is very specific to language learning for the IELTS test in terms of academic purposes. An empirical study using quantitate methods with wider IELTS learner population might result in different evidence. Additionally, considering that their learning strategies were mostly on keeping them motivated, further research on motivation to both quantitative and qualitative will explore more areas regarding IELTS mobile learning practices.

\section{CONFLICT OF INTEREST}

The authors declare no conflict of interest.

\section{AUTHOR CONTRIBUTIONS}

Soulaya Lestary carried out all the research processes, including analyzing the data and wrote the paper.

\section{ACKNOWLEDGMENT}

Soulaya Lestary thanks Hannah Rumble for her supervision and recommendation and Alison Oldfield for her kind help and recommendation as well.

\section{REFERENCES}

[1] D. Crystal, English as a Global Language, Cambridge University Press, Cambridge, 2016.

[2] A. Kukulska-Hulme, H. Lee, and L. Norris, Mobile Learning Revolution: Implications for Language Pedagogy, 2017.

[3] G.-J. Hwang and C.-C. Tsai, "Research trends in mobile and ubiquitous learning: A review of publications in selected journals from 2001 to 2010," Br. J. Educ. Technol., vol. 42, no. 4, pp. 65-70, 2011.

[4] J. Sandberg, M. Maris, and K. D. Geus, "Mobile English learning: An evidence-based study with fifth graders," Comput. Educ., vol. 57, no. 1, pp. 1334-1347, 2011.

[5] X. Chen and G. Kessler, "Tablets for informal language learning: Student usage and attitudes," Action Res. Tablets Informal Lang. Learn. Student Usage Attitudes, vol. 17, no. 1, pp. 20-36, 2013.

[6] T. M. Miangah and A. Nezarat, "Mobile-assisted language learning," Int. J. Distrib. Parallel Syst., vol. 3, no. 1, pp. 309-319, 2012.

[7] J. Byrne and R. Diem, "Profiling mobile english language learners," JALT CALL J., vol. 10, no. 1, pp. 3-19, 2014.

[8] C. Lai and D. Zheng, "Self-directed use of mobile devices for language learning beyond the classroom," ReCALL, vol. 30, no. 3, pp. 299-318, 2018.

[9] R. Phillipson, Linguistic Imperialism, Oxford University Press, Oxford. 1992.

[10] P. Howson, The English Effect, British Council, London, 2013.

[11] H. Banov, A. Kammerer, and I. Salciute, "Mapping generation Z in Indonesia: Attitudes toward international education programs," AFS Glob. Res. Study, pp. 1-13, 2017.

[12] W. H. Wu et al., "Review of trends from mobile learning studies: A meta-analysis," Comput. Educ., vol. 59, 2, pp. 817-827, 2012.

[13] M. Saritepeci, A. Duran, and U. F. Ermiş, "A new trend in preparing for foreign language exam (YDS) in Turkey: Case of WhatsApp in mobile learning," Educ. Inf. Technol., pp. 2677-2699, 2019.

[14] J. Cheon, S. Lee, S. M. Crooks, and J. Song, "An investigation of mobile learning readiness in higher education based on the theory of planned behavior," Comput. Educ., vol. 59, no. 3, pp. 1054-1064, 2012.

[15] L. Rajasingham, "Will mobile learning bring a paradigm shift in higher education?" Educ. Res. Int., pp. 1-10, 2011.

[16] M. L. Koole, "Mobile learning — A model for framing mobile learning," Mob. Learn. Transform. Deliv. Educ. Train, vol. 1, pp. 25-47, 2009.
[17] J. Burston, "Twenty years of MALL project implementation: A meta-analysis of learning outcomes," ReCALL, vol. 27, no. 1, pp. 4-20, 2015.

[18] S. Loewen, D. Crowther, D. R. Isbell, K. M. Kim, J. Maloney, Z. F. Miller, and H. Rawal, "Mobile-assisted language learning: A Duolingo case study," ReCALL, pp. 1-19, 2019.

[19] L. Moeinpour, M. Nasiri, A. J. Pineh, and N. Davarpanah, "Dynamic assessment of IELTS writing task one through mobile learning in the context of Iranian EFL learners," Int. J. English Lang. Educ., vol. 7, no. 1, p. $1,2019$.

[20] A. A. Muhammed, "The impact of mobiles on language learning on the part of English foreign language (EFL) university students," Procedia Soc. Behav. Sci., vol. 136, pp. 104-108, 2014.

[21] J. Sinclair, E. J. Larson, and S. Rajendram, "Be a machine": International graduate students' narratives around high-stakes English tests," Lang. Assess. Q., vol. 16, no. 2, pp. 236-252, 2019.

[22] S. S. Liaw, M. Hatala, and H. M. Huang, "Investigating acceptance toward mobile learning to assist individual knowledge management: Based on activity theory approach," Comput. Educ., vol. 54, no. 2, pp. 446-454, 2010.

[23] L. Sha, C. K. Looi, W. Chen, and B. H. Zhang, "Understanding mobile learning from the perspective of self-regulated learning," J. Comput. Assist. Learn, vol. 28, no. 4, pp. 366-378, 2012.

[24] Y. Liu, H. Li, and C. Carlsson, "Factors driving the adoption of m-learning: An empirical study," Comput. Educ., vol. 55, no. 3, pp. 1211-1219, 2010.

[25] J. Mason, Qualitative Researching, SAGE Publications Ltd, London, 2002.

[26] B. Matthews and L. Ross, Research Methods, Pearson Education, 2010.

[27] B. L. Berg, Qualitative Research Methods for the Social Sciences. A Pearson Education Company, Needham Heights, 2001.

[28] R. K. Yin, Case Study Research Design and Methods, SAGE Publications Ltd, London, 2003.

[29] V. Braun and V. Clarke, "Qualitative research in psychology using thematic analysis in psychology using thematic analysis in psychology," Qual. Res. Psychol., vol. 3, no. 2, pp. 77-101, 2006.

[30] J. Ritchie and J. Lewis, Qualitative Research Practice: A Guide for Social Science Students and Researchers, SAGE Publications Ltd, London, 2003.

[31] O. Erstad, "The learning lives of digital youth-beyond the formal and informal," Oxford Rev. Educ., vol. 38, no. 1, pp. 25-43, 2012.

[32] C. R. P. Ajisuksmo and J. D. Vermunt, "Learning styles and selfregulation of learning at university: An indonesian study," Asia Pacific J. Educ., vol. 19, no. 2, pp. 45-59, 1999.

[33] M. M. Elaish, L. Shuib, N. A. Ghani, E. Yadegaridehkordi, and M. Alaa, "Mobile learning for English language acquisition: Taxonomy, challenges, and recommendations," IEEE Access, vol. 5, pp. 19033-19047, 2017.

[34] D. Vogel, D. M. Kennedy, and R. Kwok, "Does using mobile device applications lead to learning?" J. Interact. Learn. Res., vol. 20, no. 4, pp. 469-485, 2009.

[35] R. C. Gardner, "Social psychology and second language learning: The role of attitudes and motivation," 1985.

[36] G. Siemens, "Connectivism: A learning theory for the digital age," JITDL, vol. 1, pp. 1-8, 2014.

Copyright (C) 2020 by the authors. This is an open access article distributed under the Creative Commons Attribution License which permits unrestricted use, distribution, and reproduction in any medium, provided the original work is properly cited (CC BY 4.0).

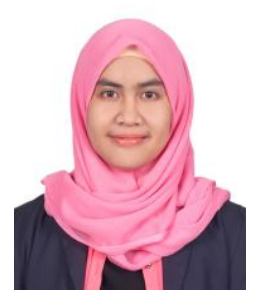

Soulaya Lestary is an M.Sc. student at the University of Bristol, UK majoring learning, technology, and society. She worked for three years at a startup Ed-Tech company which focused on online language learning. She designed e-learning concepts and managed a team during her work experiences. Since then, she has involved in Ed-Tech fields ranging from attending workshops and seminars to initiating a social project which involved online learning. 